\title{
EDITORIAL
}

\section{Late consequences of accidental exposure to inhaled irritants: RADS and the Bhopal disaster}

\author{
B. Nemery
}

Pulmonary physicians occasionally have to evaluate patients some time after an acute inhalation injury and to make a judgement about the existence of residual lung lesions, the possible causal relationship of such lesions with the accident, and their prognosis. This has been a difficult and often contentious issue, ever since former servicemen who had been gassed in the first world war, claimed compensation for late respiratory effects. Thus, in a review and opinion article published 35 yrs after the large scale use of war gases [1], it is stated that "the physical impact on men exposed to these substances has been a source of interest to, and speculation by, the medical profession, and amidst the emotional and sentimental miasma which may cloud medical opinion, much controversy and many conflicting hypotheses have been nurtured and flourished". According to the same source, leading British medical opinion in the 1930s had concluded that, although there were "cases of recurrent bronchitis, bronchiectasis and emphysema which appeared to have a clear association with severe pulmonary effects at the time of gas exposure... only a comparatively small percentage of gas casualties suffered from such ill effects and the greater bulk of men, including those with minor symptoms, received no permanent damage". Similarly, a US Board of Medical Officers found that "the most significant observation was that the major proportion (of gas casualties evacuated to field medical units) exhibited complete recovery" [1].

Reading the early literature with today's eyes, it is striking that the assessment of possible sequelae of past inhalation injury consisted solely of a clinical judgement based on the documentation of a severe (i.e. incapacitating) lung or bronchial injury, followed within a short time by an unbroken train of signs and symptoms indicative of bronchitis or emphysema, and the absence of a more plausible cause (e.g. influenza or tuberculosis). Thus, in the review article published in 1954 [1], no mention is made of "asthma" or "pulmonary function measurements", or even smoking. Over the following decades, relatively little progress was made in the debate about the occurrence of sequelae in survivors of acute inhalational injury. There were occasional reports of bronchiectases, bronchiolitis obliterans or obstructive lung disease following massive exposures to ammonia, oxides of nitrogen, sulphur dioxide, chlorine or phosgene, as well as limited follow-up studies of vic-

Correspondence: B. Nemery, Laboratorium voor Pneumologie (Eenheid voor longtoxicologie), K.U. Leuven, Herestraat 49, B-3000 Leuven, Belgium. tims of civil disasters, such as explosions, fires or major chemical spills, which involved a few tens of subjects at most. Although these studies provided evidence of persistent obstructive defects in some subjects, until the early 1980s, the prevailing opinion, judging from two leading textbooks $[2,3]$, was that "complete recovery" was the rule for most individuals surviving acute exposure. As late as 1987, an extensive review article [4] considered that "the chronic effects of acute exposures to toxic inhalants have not been clearly characterized". Although this is still true to a large extent, significant progress has been made over the past $10 \mathrm{yrs}$, mainly as a result of the "discovery" of the reactive airways dysfunction syndrome (RADS).

\section{From RADS to irritant-induced asthma}

In 1985, the issue of the late consequences of inhalation injury received a new impetus with publication by BROOKS et al. [5], of a retrospective analysis of 10 previously healthy subjects, who had developed persistent airway hyperreactivity after a single, high level exposure to a chemical irritant. The authors called the condition "reactive airways dysfunction syndrome" or RADS, presumably as an oblique reference to the adult respiratory distress syndrome (ARDS). The acronym RADS has proved to be very successful and has rapidly gained wide acceptance in the medical community, even though the "reactive airways dysfunction syndrome" is a somewhat nondescript (and grammatically suspect) phrase. Indeed, dysfunction because of reactive airways is a feature of any asthma and, in this sense, the term RADS is not particularly helpful to indicate that the syndrome originates from a single inhalation. Perhaps "postinhalation injury hyperreactivity" or a similar term would have been more appropriate. The great merit of RADS is that a respectable and "marketable" name had, at last, been given to a clinical entity, with which practising pneumologists were regularly faced but for which little or no published evidence had hitherto been available to sustain the claim that asthma symptoms could be the consequence of an inhalation incident. Until the RADS era, victims of inhalation incidents were considered to have recovered completely if no structural alterations were demonstrated by radiology or bronchoscopy, or if their pulmonary function values were "within normal limits". Henceforth, the presence of bronchial hyperreactivity, which can be demonstrated by a low provocative concentration or dose of histamine or methacholine causing a $20 \%$ fall in forced expiratory volume in one 
second (PC20 or PD20), must be taken into consideration as a possible consequence of severe inhalation injury.

Since the seminal publication of Brooks et al. [5], many authors have published case reports, case series and, so far, a single cohort study [6] demonstrating the reality of RADS. Several recent editorials, reviews or textbook chapters have been devoted to the condition, and these have indicated that, far from being a simple curiosity, RADS does occur in a proportion of survivors of inhalation trauma [7-11]. The exact incidence of RADS, either in the community or among victims of inhalation accidents, is still unknown. An evaluation based on data from poison control centres indicated that RADS is uncommon, with only $6 \%$ of victims of (generally mild) inhalation injury exhibiting symptoms for more than 2 weeks [12]. On the other hand, 3 out of 14 health workers "highly" exposed to vapours of spilled acetic acid were later found to fit the diagnostic criteria for RADS, although none of these subjects seems to have experienced very serious respiratory injury [6]. There is clearly a need for a better confirmation and reporting of this condition.

RADS has been described as a possible consequence of inhalation accidents in the most varied settings, including many sectors of industry, in agriculture and the health sector [6], the home and the community [13]. The causal exposures have been generally described as "high levels of irritants", with the incriminated agents varying from well-known and defined gases or vapours, such as chlorine or ammonia, to complex and ill-defined mixtures, such as fire smoke, paints, pesticide degradation products [13], or swine confinement gases [14]. For obvious reasons, quantitative exposure assessments have generally been lacking, but surrogate measures, such as distance from the source and/or duration of exposure $[6,13]$, have been used to estimate exposure levels, with, however, mixed success in establishing exposure-response relationships.

At present, the main question is no longer whether RADS does or does not exist as a clinical entity, but what the determinants are for its occurrence in some victims of inhalation injuries. Indeed, the recognition that persistent airway hyperreactivity may accompany or follow the repair of airway injury should not detract us from the fact that even severe airway injury is not invariably followed by RADS. This has recently been shown in a study of burns victims, in whom smoke inhalation and tracheobronchial injury had been welldocumented by bronchoscopy and yet no bronchial hyperreactivity was found 1-7 yrs later [15]. It is important to determine whether the occurrence of RADS can be prevented by specific therapeutic measures (e.g. administering corticosteroids, avoiding oxygen administration) during the management of the acute phase. Both clinical-epidemiological and experimental work should be encouraged in this area, especially since it is likely that clues about the exact pathogenesis of RADS will be of great scientific value in the wider perspective of clarifying the pathogenesis of asthma in general. In this respect, interesting though somewhat conflicting data have been published on the cellular pathology of RADS [16, 17].

Besides the important theoretical questions regarding pathogenesis, the concept of RADS also involves a number of other very practical issues, mainly with regard to diagnostic criteria, prognosis, treatment and compensation. A particular, and often difficult, problem concerns the "reactivation" of latent asthma (e.g. in an asymptomatic individual with a history of asthma in childhood) or the worsening of pre-existing asthma following an accidental inhalational exposure. Although, on the basis of the strictest criteria [5], a diagnosis of RADS should not be made in subjects with prior respiratory complaints, it appears perfectly reasonable to consider that persistent exacerbation of asthma is a possible consequence of acute inhalation injury. Several authors seem to have adopted this view [13, 18]. In fact, it is conceivable (and there is some evidence to support this hypothesis [12]) that asthmatics or "ex-asthmatics" or, more generally, subjects with less than optimal airways (e.g. smokers) are at greater risk of suffering longterm effects of inhalation injury than perfectly healthy people. In other words, compensation should not be denied to a victim of inhalation injury simply on the grounds that there was evidence of pre-existing asthma or smoking-related lung disease, although, admittedly, the documentation and quantification of the contribution of the accident will be more complicated in such cases.

An important practical consequence is that adequate documentation of pulmonary status, which includes at least simple spirometry, should be available for the largest possible number of people. This is a task for school medical services, general practitioners, occupational physicians and all those involved in preventive or primary health care. For those at special risk of inhalation injury, such as some chemical workers, firefighters and other emergency personnel, etc., it is reasonable to recommend that a measure of bronchial responsiveness be obtained at the onset of their career (although not for the purpose of excluding subjects with bronchial hyperresponsiveness from such jobs).

The recognition that asthma may be caused by a single exposure to high levels of irritants has naturally led to extending this notion to the possibility that other types of irritant injury to the airways would have similar effects. Thus, repeated, but less dramatic and often poorly documented occupational exposures to (excessive levels of) nonsensitizing irritants have also been claimed to lead to asthma, and this condition has been labelled "irritant-induced asthma" [19]. It is now wellrecognized, mainly from observations of pulpmill workers, who frequently experience gassing incidents with chlorine or related irritants, that such patterns of peak exposure may lead to chronic changes in pulmonary function [20,21], and bronchial hyperresponsiveness or asthma [17, 22]. In fact, it is now considered that RADS represents a particular subset of irritant-induced asthma, namely the form that originates from a single incident [23].

\section{The Bhopal disaster and long-term consequences of acute inhalation injury}

An event that should have been of major significance in the discussion about the sequelae of acute inhalation 
injury is the Bhopal disaster, which was caused by the accidental release of about 30 tons of methyl isocyanate (MIC) on the night of December 2-3, 1984 [24-26]. In what has been the worst acute chemical incident in history, more than 2,500 people died acutely, mostly from pulmonary oedema (but, incidentally, also hyperacutely, by what mechanism?), and many thousands suffered from acute ocular and respiratory symptoms. Whilst the acute symptomatology has been relatively well-described in various publications [25, 27], it must be recognized that, in the 10 yrs that have followed the catastrophe, very little useful epidemiological information has been produced regarding the long-term respiratory consequences $[25,28]$.

Animal experiments carried out in the wake of the Bhopal disaster have shown that MIC is an extremely irritating chemical, that it causes bronchial lesions and, when given at a high enough dose, pulmonary oedema [25, 29-31]. On the whole, animals surviving the acute episode have shown remarkable recovery, although residual lesions in the airways, including possible obliterative bronchiolitis, have occasionally been found [32].

Follow-up examinations of MIC-exposed subjects have shown a variety of radiological and functional lesions indicative both of pulmonary fibrosis and bronchial obstruction [25, 33]. In most published studies, the observation period has not extended beyond 2 yrs and the data available do not allow us to judge the prevalence of such lesions in the exposed population, because little or no information is provided about the recruitment of patients who underwent more sophisticated examinations. In this issue of the Journal, VIJAYAN and SANKARAN [34] present interesting data from studies carried out on 60 patients some time (1-7 yrs) after the Bhopal accident. They show persisting airway or alveolar inflammatory changes (with macrophages and neutrophils, but also lymphocytes) which correlate reasonably well not only with a crude, but ingenious, index of intensity of exposure, but also with at least some indices of ventilatory impairment. Unfortunately, asthma symptoms were not elicited and response to bronchodilator or nonspecific bronchial reactivity were not measured in this study, and it is therefore not possible to verify whether some of the subjects studied suffered from RADS. The reported inflammatory cell profile in the lavage is only partly consistent with the reported pathology of RADS [16].

VIJAYAN and SANKARAN [34] should be commended for having carried out such clinical investigations in circumstances that are obviously much more difficult than in Europe or North America. However, it is sad to see that very little, if any, epidemiological mileage can be gained from their work or from other published studies [28]. The Indian Council for Medical Research has been in charge of the research on the after effects of the Bhopal disaster, but no useful data (assuming the information has been collected in a useful manner) have been released so far [35]. One would have liked to see properly designed follow-up studies of well-defined and appropriately selected cohorts of exposed and nonexposed subjects from Bhopal. Such studies would have looked at respiratory symptoms, simple pulmonary function parameters and nonspecific bronchial hyperreactivity, to name only the most relevant respi- ratory endpoints. In view of the very large number of subjects affected (thousands, as opposed to the few tens, at most, in other inhalation accidents), the existence of a wide range of exposures (from lethal to minimal), and the very well identifiable time of exposure, such a study would have been of enormous value in providing answers to questions such as: the natural evolution of inhalation injury; the proportion of subjects who are left with persistent structural or functional pulmonary damage; the existence (or not) of relationships between this impairment and irritant level or severity of the initial injury; the incidence of RADS and its determinants and evolution, with or without therapy, etc. It should be pointed out that measuring nonspecific bronchial hyperreactivity for epidemiological purposes is both feasible, with relatively little logistic constraints or costs (compared to chest imaging or bronchoscopy), and acceptable. The latter is even more true in view of the possible therapeutic consequences of a positive finding.

Clearly, the most important consequence of the Bhopal tragedy has been the amount of suffering borne by the victims, the majority of whom, to add insult to injury, do not appear to have received adequate compensation $[35,36]$. Bhopal has also highlighted the need for adequate prevention of major industrial hazards and the implications of exporting hazardous chemicals and work processes to the third world [26, 28]. Although the medical management of the acute emergency seems to have been as appropriate as it could have been in the circumstances, one of the sad sides of the Bhopal saga is the fact that the scientific information which could have been gained from the disaster, once it had occurred, does not seem to have been exploited fully and adequately. In this way, and without being cynical, the Bhopal toxic gas disaster, until now, represents a "lost experiment" with regard to the evaluation of its longterm health consequences. Nevertheless, even after more than $10 \mathrm{yrs}$, it should be possible to try and look at the prevalence of RADS in a representative sample of subjects. To paraphrase a recent editorial [37], it is not too late for sound respiratory epidemiology in Bhopal. Perhaps the European Respiratory Society could be of assistance in this endeavour.

\section{References}

1. Penington AH. War gases and chronic lung disease. Med J Aust 1954; 1: 510-516.

2. Parkes WR. Occupational Lung Disorders. 2nd Edn. London, Butterworths, 1982.

3. Morgan WKC, Seaton A. Occupational Lung Disorders. Philadelphia, W.B. Saunders, 1975.

4. Schwartz DA. Acute inhalation injury. State of the Art Reviews in Occupational Medicine 1987; 2: 297-318.

5. Brooks SM, Weiss MA, Bernstein IL. Reactive airways dysfunction syndrome (RADS): persistent asthma syndrome after high level irritant exposures. Chest 1985; 88: 376-384.

6. Kern DG. Outbreak of the reactive airways dysfunction syndrome after a spill of glacial acetic acid. $A m$ Rev Respir Dis 1991; 144: 1058-1064.

7. Nemery B. Possible long-term effects of acute inhalation injury. Cahiers Méd Trav Cahiers voor Arbeidsgeneeskunde 1994; 31: 19-23. 
8. Kennedy SM. Acquired airway hyperresponsiveness from nonimmunogenic irritant exposure. State of the Art Reviews in Occupational Medicine 1992; 7: 287-300.

9. Kern DG, Sherman CB. What is this thing called RADS? Chest 1994; 106: 1643-1644.

10. Newman Taylor AJ. Respiratory irritants encountered at work. Thorax 1996; 51: 541-545.

11. Brooks SM, Bernstein IL. Reactive airways dysfunction syndrome or irritant-induced asthma. In: Asthma in the workplace. Bernstein IL, Chan-Yeung M, Malo JL, Bernstein DI, eds. New York, Basel, Hong Kong, Marcel Dekker, 1983; pp. 533-549.

12. Blanc PD, Galbo M, Iliatt P, Olson KR. Morbidity following acute irritant inhalation in a population-based study. J Am Med Assoc 1991; 266: 664-669.

13. Cone JE, Wugofski L, Balmes JR, et al. Persistent respiratory health effects after a metam sodium pesticide spill. Chest 1994; 106: 500-508.

14. Cormier Y, Coll B, Laviolette M, Boulet LP. Reactive airways dysfunction syndrome (RADS) following exposure to toxic gases of a swine confinement building. Eur Respir J 1996; 9: 1090-1091.

15. Bourbeau J, Lacasse Y, Rouleau MY, Boucher S. Combined smoke inhalation and body surface burns injury does not necessarily imply long-term respiratory health consequences. Eur Respir J 1996; 9: 1470-1474.

16. Gautrin D, Boulet L-P, Boulet $\mathrm{M}$, et al. Is reactive airways dysfunction syndrome a variant of occupational asthma? J Allergy Clin Immunol 1994; 93: 12-22.

17. Chan-Yeung M, Lam S, Kennedy SM, Frew AJ. Persistent asthma after repeated exposure to high concentrations of gases in pulpmills. Am J Respir Crit Care Med 1994; 149: 1676-1680.

18. Boulet LP. Increases in airway responsiveness following acute exposure to respiratory irritants: reactive airway dysfunction syndrome or occupational asthma. Chest 1988; 94: 476-481.

19. Tarlo SM, Broder I. Irritant-induced occupational asthma. Chest 1989; 96: 297-300.

20. Kennedy SM, Enarson DA, Janssen RG, Chan-Yeung $\mathrm{M}$. Lung health consequences of reported accidental chlorine gas exposures among pulpmill workers. Am Rev Respir Dis 1991; 143: 74-79.

21. Torén K, Hagberg S, Westberg H. Health effects of working in pulp and paper mills: exposure, obstructive airways diseases, hypersensitivity reactions, and cardiovascular diseases. Am J Ind Med 1996; 29: 111-122.

22. Bhérer L, Cushman R, Courteau JP, et al. Survey of construction workers repeatedly exposed to chlorine over a three to six month period in a pulpmill. II. Follow- up of affected workers by questionnaire, spirometry, and assessment of bronchial responsiveness 18 to 24 months after exposure ended. Occup Environ Med 1994; 51: 225-228.

23. Bernstein IL, Chan-Yeung M, Malo JL, Bernstein DI (Editors). Asthma in the workplace. New York, Basel, Hong Kong, Marcel Dekker, 1993.

24. Anonymous. Calamity at Bhopal. Lancet 1984; ii: 1378-1379.

25. Mehta PS, Mehta AS, Makhijani AB. Bhopal tragedy's health effects: a review of methyl isocyanate toxicity. $J$ Am Med Assoc 1990; 264: 2781-2787.

26. Dhara R, Dhara VR. Bhopal: a case study of international disaster. Int J Occup Environ Med 1995; 1: 58-69.

27. Misra NP, Pathak R, Gaur KJBS, et al. Clinical profile of gas leak victims in acute phase after Bhopal episode. Ind J Med Res 1987; 86 (Suppl.) 11-19.

28. Koplan JP, Falk H, Green G. Public health lessons from the Bhopal chemical disaster. J Am Med Assoc 1990; 264: 2795-2796.

29. Nemery B, Dinsdale D, Sparrow S, Ray DE. Effects of methyl isocyanate on the respiratory tract of rats. $\mathrm{Br} \mathrm{J}$ Ind Med 1985; 42: 799-805.

30. Nemery B, Dinsdale D, Sparrow S. The toxicity of inhaled methyl isocyanate in experimental animals: a review of studies published less than two years after the Bhopal disaster. Bull Eur Physiopathol Respir 1987; 23: 315322.

31. Bucher JR. Methyl isocyanate: a review of health effects research since Bhopal. Fund Appl Toxicol 1987; 9: 367-379.

32. Dinsdale D, Nemery B, Sparrow S. Ultrastructural changes in the respiratory tract of rats following methyl isocyanate inhalation. Arch Toxicol 1987; 59: 385-390.

33. Kamat SR, Patel MH, Pradhan PV. Sequential respiratory, psychologic, and immunologic studies in relation to methyl isocyanate exposure over two years with model development. Environ Health Perspect 1992; 97: 241253.

34. Vijayan VK, Sankaran K. Relationship between lung inflammation, changes in lung function and severity of exposure in victims of the Bhopal tragedy. Eur Respir J 1996; 9: 1977-1982.

35. Kumar S. India: the second Bhopal tragedy. Lancet 1993; 341: 1205-1206.

36. Lepkowski W. Ten years later Bhopal. Chem Eng News 1994; December 19: 8-18.

37. Dhara VR, Kriebel D. The Bhopal gas disaster: it's not too late for sound epidemiology. Arch Environ Health 1993; 48: 436-437. 